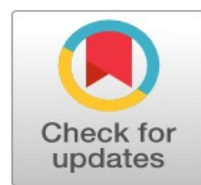

\title{
A study on the application of institutional research to reinforce the financial function of senior high schools
}

\author{
Shu-Fang Lin $^{1 *}$, Yih-Jeng Lin ${ }^{2}$, Ching-Ling Wu ${ }^{3}$ \\ 1,3 Department of Educational Policy and Administration, National Chi Nan University, Nantou County, \\ Taiwan \\ ${ }^{2}$ Department of Information Management, Chienkuo Technology University, Changhua, Taiwan
}

\author{
Index Terms \\ Institutional research \\ Low birth rate \\ Financial function \\ Business intelligence
}

Received: 1 February 2017

Accepted: 20 April 2017

Published: 30 June 2017

\begin{abstract}
Institutional Research has already developed more than 50 years in the United States and it contributes to produce evidence-based decisions and strategies for universities including planning, programs designing and financial decision-making. Today's Taiwan is facing the challenges of low birth rate, parental choices, parent's right to education and population urbanization. Low birth rate has direct and the most negative influence on school management among the above factors. Not only universities but all levels of schools in Taiwan are challenged how to manage and function well. Senior high schools in Taiwan generally left themselves behind the educational revolution before. However more and more administrators, teachers, parents and even students now have started to pay attention to the fierce revolution in education especially those critical and influential ones. Hence, we believe Institution Research concepts will start to root in the senior high schools in confronting the tough school affairs. In this paper, we try to apply institutional research to reinforce the financial function of senior high schools. This study contributes to exploring the potential and limitation of Institution Research on senior high schools' financial function. A new vision of senior high schools' financial management is hopefully to be created in this study.
\end{abstract}

(c) 2017 The Author(s). Published by TAF Publishing.

\section{INTRODUCTION}

According to the Ministry of the Interior's latest statistics, Taiwan's birth rate continues to decline. The annual crude birth rate was $9.63 \%$ in November of 2016. Comparing with the same month in 2015, it decreased by 821 people with the growth rate of $-4.10 \%$. The crude death rate is $6.8 \%$. Comparing with the same period in 2015, it reduced by 118 people with an increase rate of $-0.86 \%$. Furthermore, in 2016 academic year, the senior high schools of 15 school districts in the Taiwan planned to recruit 251,204 students; however, the total amount of potential enroller was only 204,584 . That means the total amount of senior high students' recruiting is higher than actual amount of enrollment. Among the 15 school districts, schools located in north districts draw most students and the central districts take the second place. The southern districts are the third. On the average, each student has an opportunity to attend 1.23 schools. In other words, students and their parents have lots of choices to attend which school they prefer. Low birth rate, parental choice in education and population urbanization cause difficulties in school's management. Among them, the low birth rate is the most problematic. Shortage of students' amount will cause the lessening of schools' income. Lacking in financial support

\footnotetext{
* Corresponding author: Shu-Fang Lin

†Email: yclin@ctu.edu.tw
} 
will result in poor schools' construction and development.

Then less and less students will come. A vicious circle of school management will be created very soon. Accordingly, senior high schools actually have no choices but to equip themselves well to face the intense and harsh challenges of students' recruitment. All schools try hard to find solution to the above serious students' recruitment problems so as to maintain the development and even "existence" of schools.

To help senior high schools deal with the difficulties of school management affairs and students' recruitment, this study tries to apply the Institutional Research concept and strategies in senior high schools and focus on their financial structure. As we know, the field of Institutional Research (IR) is over 50 years old and embedded in nearly every college and university in the United States and many others around the world. IR is used for supporting campus leaders and policy makers in wise planning, programming, and fiscal decisions covering a broad range of institutional responsibilities. Those areas can include research support to senior academic leaders, admissions, financial aid, curriculum, enrollment management, staffing, student life, finance, facilities, athletics, alumni relations and many others (Association for Institutional Research, 2014). Being faced by numerous educational challenges, Taiwan Association for Institutional Research (TAIR) was established in the Jan. of 2016.

It is believed that IR concepts and trends will start to grow stronger and stronger theoretically and empirically in Taiwan. Senior high schools now are confronted with the impact of less and less students' source, so they need more creative and effective strategies to deal with their tough situations immediately. IR can be a good alternative as they try hard to strengthen and enforce their entity of school administration and management. In this tough situation, we once designed a multiple-factored model of Institutional Research in a senior high school and investigate a senior high school's experiment of (IR), aiming to provide evidencebased decision making support to student recruitment policies and practices. That IR model is structured with four analysis modules: (1) Enrollment Source Analysis; (2) School satisfaction questionnaire analysis; (3) Analysis of Learning Status and (4) Analysis of Teachers' Instructional Quality. Then the above four analysis modules expand into 25 analysis pages as below. (1) The trend analysis of the enrollment from competitor; (2) Scores Analysis of Admission placement; (3) Analysis of the sources of studentsschool sources/regions; (4) Analysis of the ways students choose for admission; (5) Reputation Impact analysis; (6) Environmental impact analysis; (7) Teacher education and qualifications analysis; (8) Environmental equipment impact analysis; (9) Student Affairs Counseling impact analysis; (10) Course Teaching Effect analysis; (11) Interaction Analysis for social community; (12) Diagnosis and analysis of grades; (13) Analysis of individual student's starting aptitude; (14) Academic Performance Analysis; (15) Diagnosis of test questions; (16) Teaching assessment analysis -overall analysis; (17) Teaching hours load analysis; (18) Curriculum design index analysis; (19) Index for teaching materials compilation analysis; (20) Multiple perspective index analysis; (21) Adaptive learning index analysis; (22) Effective teaching index analysis; (23) Course improvement Index analysis; (24) Classroom management index analysis; (25) Remedial teaching Index analysis (Lin \& Lin, 2016a). However, the limitation of that previous model motivates us to rethink and redesign our IR model for senior high schools. A brand-new, complete and overall Institutional Research model for senior high schools was proposed. This model divides into three stages including (1) students' enrollment, (2) school attendance and (3) graduates' career development stages as the developmental process after students enroll (Lin \& Lin, 2016b).

We hope something different and new can happen in senior high schools' management and decision systems. The school's financial structure is like the digestive system of human and shortage of students will directly affect the income of a school. Therefore, we try to explore the low birth rate's negative influence on schools' funding and try to apply IR to enforce their financial function. Precisely speaking, we take the financial simulation analysis for example to demonstrate how to use the IR model. As a strong financial structure is established successfully and that can contribute to schools' good operation. Additionally, a new vision of senior high schools' financial management is hopefully to be created in this study. With this study, we also hope to exam our IR model's fitness and effectiveness. Accordingly, this paper will explore two questions namely:

1. What is the complete and overall Institutional Research model for senior high schools?

2. How to apply this Institutional Research model in senior high schools' financial function effectively?

\section{LITERATURE REVIEW}

\section{The Influence of Low Birth Rate}

The total fertility rate of Taiwan in 2008 was $1.05 \%$ and that was the least all around the world at that time. From 
2012 to 2014, the rate was maintained between the range of $1.065 \% \sim 27 \%$ (Ministry of the Interior, 2016). Furthermore, with an estimation of mortality and birth rate, Taiwan's negative population growth age will eventually come in 2025. Furthermore, according to the Ministry of the Interior's latest statistics, Taiwan's birth rate continues to decline. The annual crude birth rate was $9.63 \%$ in the November of 2016. Comparing with the same month in 2015 , it decreased by 821 people with the growth rate of $-4.10 \%$.

The low total fertility rate and birth rate caused the huge change of Taiwan's population structure. Schools around Taiwan currently are challenged by serious student recruitment difficulties resulted from low birth rate. The harsh challenge from low birth rate in Taiwan has seriously impacted education. No children, there will also be no need for teachers and schools. Shortage of students' amount will cause the lessening of schools' income. Lacking in financial support will result in poor schools' construction and development.

Then less and less students will come. A vicious circle of school management will be created very soon. Low birth rate affects not only universities but also elementary schools and secondary education. As we know, in Taiwan's 2016 academic year, 35\% universities failed to recruit enough students and the total amount of senior high school students' recruiting is higher than actual amount of enrollment.

Schools in Taiwan face serious problem and difficulty in students' recruiting resulting from not only too many schools to compete but also low birth rate indeed. Administrators of schools need new and effective strategies to improve their school management and attract more students to enroll. However in Taiwan now, only universities have the power and competency to conduct IR. Furthermore, Taiwan's Association for Institutional Research was just established in January of 2016. Till now, this study is the first and the only one to propose an IR model for senior high schools. Hopefully, we will start an amazing journey of IR since now.

\section{Institutional Research}

In 1940 IR was proposed to effectively deal with American Universities' management issues. However how old is IR? What is IR? Why has IR been introduced in hundreds of universities globally? Institutional research has been a significant feature in the management of higher education in the United States for more than half a century.
Today, most U.S. universities have dedicated offices of institutional research. The establishment of the Association for Institutional Research (AIR) in the 1960s began the process of formalizing the establishment of a cadre of institutional researchers in the United States and the development of an identifiable "community of practice" in the United States, with its own culture and expectations, and its own routes for professional recognition, career progression, and ongoing professional development (Taylor, Hanlon \& Yorke, 2013; Pathumporn \& Nakapaksin, 2015).

What is IR? Defining IR is not an easy task. Most definitions emphasize the functional aspects of IR and note that it is directed towards the support of management at an institution: 'what distinguishes institutional research stricto sensu is its application to the individual establishment of higher education' (Neave, 2003:3-4). Saupe (1981) provides a similar and highly influential definition of IR: 'research conducted within an institution of Studies in Higher Education 457 higher education in order to provide information which supports institutional planning, policy formulation and decision making'. There have also been efforts to provide a generalized definition that is broad enough to accommodate various functions and characteristics of IR.

Terenzini (1993) considers IR to be 'organizational intelligence' and states that it refers 'to the data gathered about an institution, to their analysis and transformation into information, and to the insight and informed sense of the organization that a competent institutional researcher brings to the interpretation of that information' (quoted from Chirikov, 2013). Moreover, Volkwein (2015) thinks that there are three concepts involving IR critical to school management: (1) school affairs reports and strategies analysis; (2) planning, student recruitment, and financial management; (3) quality assurance, learning achievement assessment, program evaluation, efficacy and certificates (Webber et al., 2015; Rijal, 2016).

Additionally, based on experience in Europe and Australasia, it is possible to outline an alternative functional typology for institutional research: (1) Routine institutional management, including formal internal and external reporting and operations support. (2) Strategy formation, including modeling and scenario planning. (3) Quality assurance and quality enhancement. (4) Marketing and competitive data analysis (Taylor et al., 2013). Being faced with numerous educational challenges TAIR was established in January of 2016. It is believed that IR concepts and trends will start to grow stronger and stronger theoretically and empirically in Taiwan. Senior high schools in Taiwan now 
are confronted with the impact of less and less students' source, so they need more creative and effective strategies to deal with their tough situations immediately. IR can be a good alternative.

\section{Financial Structure in Senior High Schools}

Organizations, whether public or private, for-profit or notfor-profit, all need to face financial problems (Chen, 2004). Even the senior high schools are the same. Furthermore, financial problems have not always been the school's own business, but will draw much attention instead. Financial system to the body is exactly like the digestive system to the human body.

Now basic concepts of the financial system are described as follows: (A) The financial system The financial system takes the accounting system as the center, and contains three parts including budgeting, fund scheduling, asset and liability management to provide timely and useful financial information to the operating system (Liu, 1996). (B) Public and private education budget system Public and private education budget system in Taiwan was developed by educational and administrative organizations. The process is very complicated and the budget system is not sensitive to the change of environment.

Particularly, public education institutions use most funds of Taiwan's overall education funding and if the education budget system is not applicable, it will have negative influence on the distribution and application of educational resources (Chen, 2004). (C) The public and private senior high schools' financial structure Schools' financial structure contains subsidy from government, tuition, donation and others. Tuition means the fee that educators charge and the educated need to pay directly (Li, 1992).

Public schools' income mainly comes from subsidy from government and tuition; their expenditure contains personnel cost, administrative/instructional cost and their construction and equipment cost. On the other hand, "Act for Establishing the National Senior High School Affairs Fund" described its aim as below. The possible sources of income were listed in Table 1. This Act shows us that there are strict regulation and limitation of public school's financial structure and system.

"In order to respond accordingly to senior secondary education development trends, enhance the quality of education, and facilitate schools' ability to undertake and manage their financial affairs, this Act to establish national senior high school affairs funds has been formulated" (Laws and regulations database of the Republic of China, 2015).
TABLE 1. National senior high school affairs funds sources

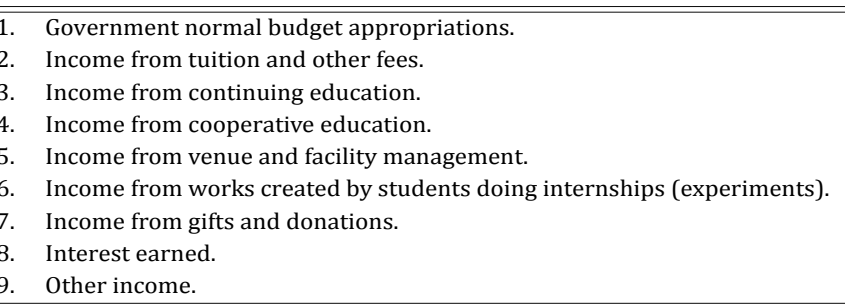

\section{METHODOLOGY}

After literature review and reference to our empirical experience, an Institutional Research model was proposed. Based on school affairs of senior high schools, this study includes all aspects of school management issues and investigates thematically. This model can provide evidence-based strategies with the application of BI analytic software for senior high schools' management. In this study, we take the financial simulation analysis for example to demonstrate how to use the IR model.

\section{Research Method and Process}

In the beginning, researchers took action to conduct literature review and integration, then we focused on the school affairs of senior high schools. After that, we proposed an Institutional Research model for senior high schools. Then we demonstrated how to use the IR model with the example of financial function analysis. If real data are available in the near future, we will use to analyze and produce databased suggestion or strategies for senior high schools. The research method and process is as Figure 1 shows.

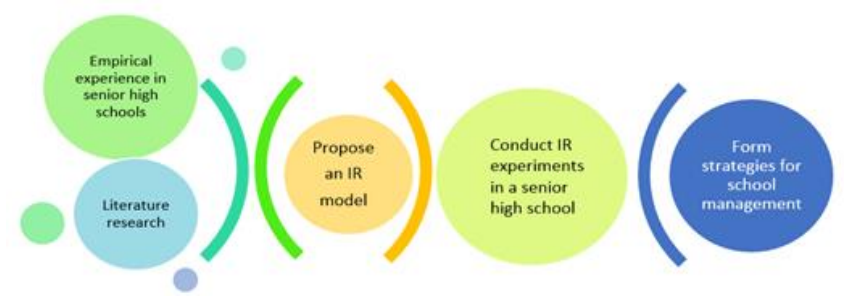

FIGURE 1. Research method and procedure

\section{Research Instrument}

Institutional Research is the core concept of this study. Most Institutinal Research works use BI analytic software " QlikView" as analysis tool and now we intorduce the function of "QlikView" as follows:

QlikView is the most flexible Business Intelligence platform for turning data into knowledge. More than 24,000 organizations worldwide have enabled their users to easily consol- 
idate, search, and visually analyze all their data for unprecedented business insight using QlikView's simplicity. Effective decision-making is based on having the right information available and easy accessible. Taking just minutes to learn, the automatic associations of QlikView create endless possibilities for making ad hoc queries without requiring tediously defined structures and hierarchies, as is typical in other data analysis tools. QlikView promotes unrestricted analysis of application data, helping users make time-saving and accurate decisions. It brings a whole new level of analysis, insight, and value to existing data stores with user interfaces that are clean, simple, and straightforward (Visual Intelligence, 2016). Figure 2 shows us the structure of BI system.

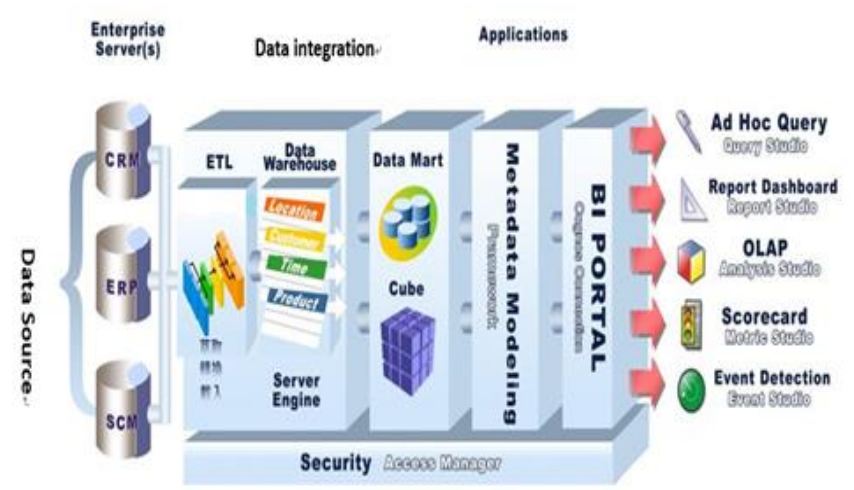

FIGURE 2. Business intelligence structure system

\section{RESULTS AND DISCUSSION}

In response to research questions, our results are as below: 1. What is the complete and overall Institutional Research model for senior high schools?

After literature review and reference to researchers' empirical experience, we proposed an IR model for senior high schools as Figure 3 shows. Figure 4 shows us the school financial management analysis module. As students enroll, they start to enjoy their campus lives. Excellent schools need to support students' need in learning activities both physically and psychologically. Then they will prepare themselves well to get deeply involved with campus, and become acquainted with school faculty and equipment. Schools utilize all funds for school affairs operation even after their students graduate.

This study proposes a Model for Senior High School's Institutional Research and we actually hope to help schools elaborate administration works and school management based on data-evidence support. Eventually, students can benefit most from this Institutional Research work or model. This model divides into three stages including (1) students' enrollment, (2) school attendance and (3) graduates' career development stages as the developmental process after students enroll. Those analyses are based on senior high schools' daily but vital affairs. With literature research and our empirical experience, we put the following facets into the analyzing themes: (1) student enrollment effect analyses, (2) school financial management, (3) learning effect analyses, (4) student guidance, (5) teaching quality analyses, (6) higher education attending ratio analyses, and (7) occupation analyses. The model is as Figure 4 shows. Each theme contains several important analyses pages as follows:

(1) Student enrollment effect analyses: Admission analysis, Student source analysis (regions), Student source analysis (junior high schools), Family background analysis, Admission scores analysis, Student multiple performance, Learning process analysis, Department choosing analysis.

(2) School financial management: Tuitions and miscellaneous fees, Personnel expense, Competition programs, Curriculum cost analysis, Enterprise donation, Construction and equipment maintenance cost analysis, Parents' Association donation.

(3) Learning effect analyses: Credits acquirement, Licenses acquirement, Student clubs attendance, Class leaders, Volunteer services, Library usage rate.

(4) Student guidance: Absence/ reward and penalty, Counseling times.

(5) Teaching quality analyses: Curriculum satisfication, Professional research and study attendance ratio, Teaching method and material design ratio, Attendance ratio of Professional Development evaluation programs for teachers.

(6) Higher education attending ratio analyses: Entrance exam scores analysis, Admission schools types analysis.

(7) Occupation analyses: Occupation area analysis, Occupation classification analysis, Salary analysis, Work stability analysis, Employer satisfication analysis.

Furthermore, student recruitment effect analyses (Nationwide), student recruitment effect analyses (school districts), faculty-student ratio analysis, faculty recruitment amount analysis, courses and departments amount analysis, learning performance analyses, students' suspense/withdrawal ratio analysis, fore-warming system (Mid-semester/Final), life adaptation analyses, faculty loss ratio analyses, graduates' career development analysis all can be put into practice under this model. IR work is a professional work and schools need to set up a unit to integrate 
the need of school administration or management to develop their own IR programs. The research results ought to be available to administrators, teachers, students and even their possible students or parents. With good quality IR work, school affairs can be studied anytime and schools can realize their social accountability. We can both realize the goal of evidence-based decision/strategies and the aim of well-functioned or managed senior high schools can come true.

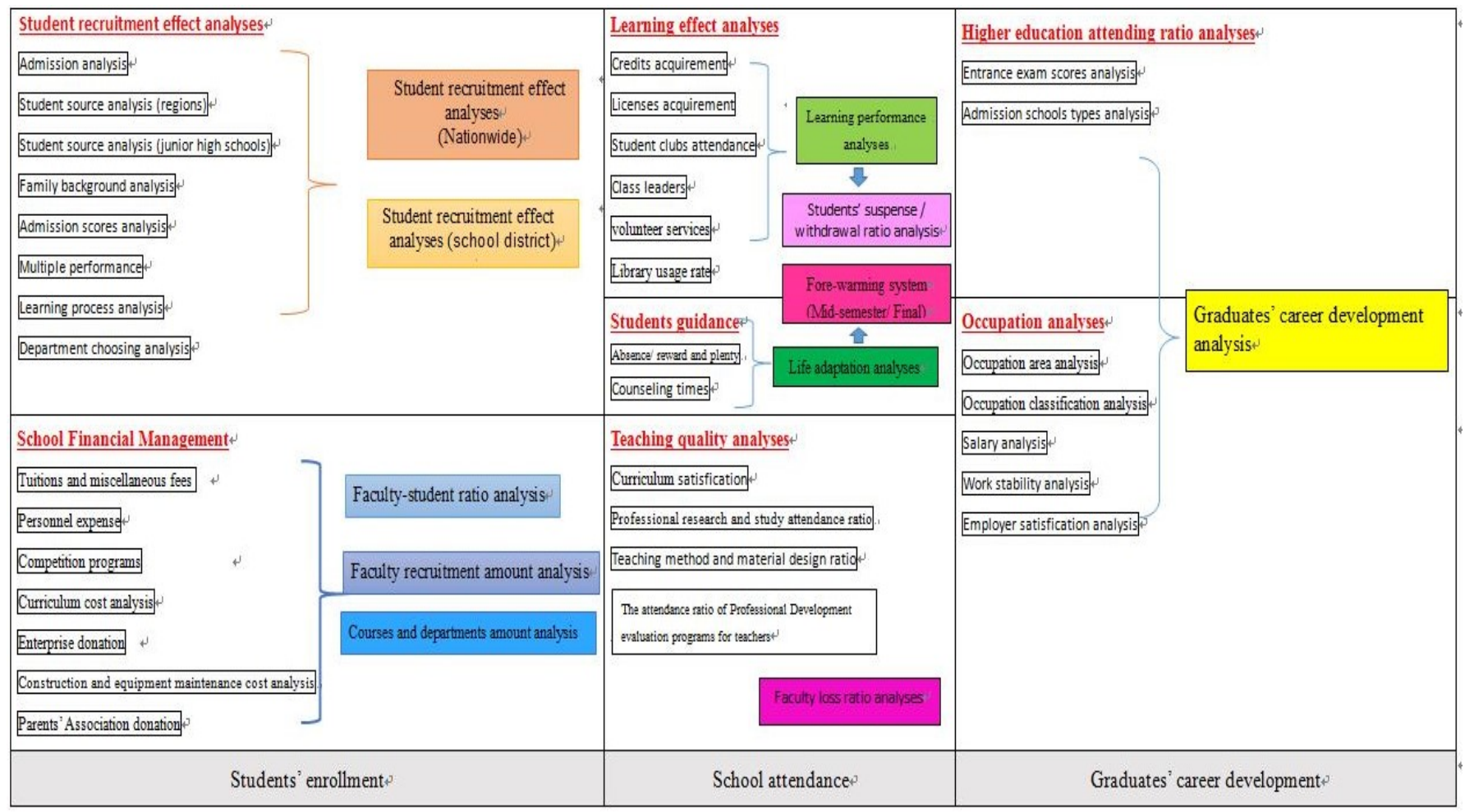

FIGURE 3. An Institutional research model for senior high schools (Lin \& Lin, 2016)

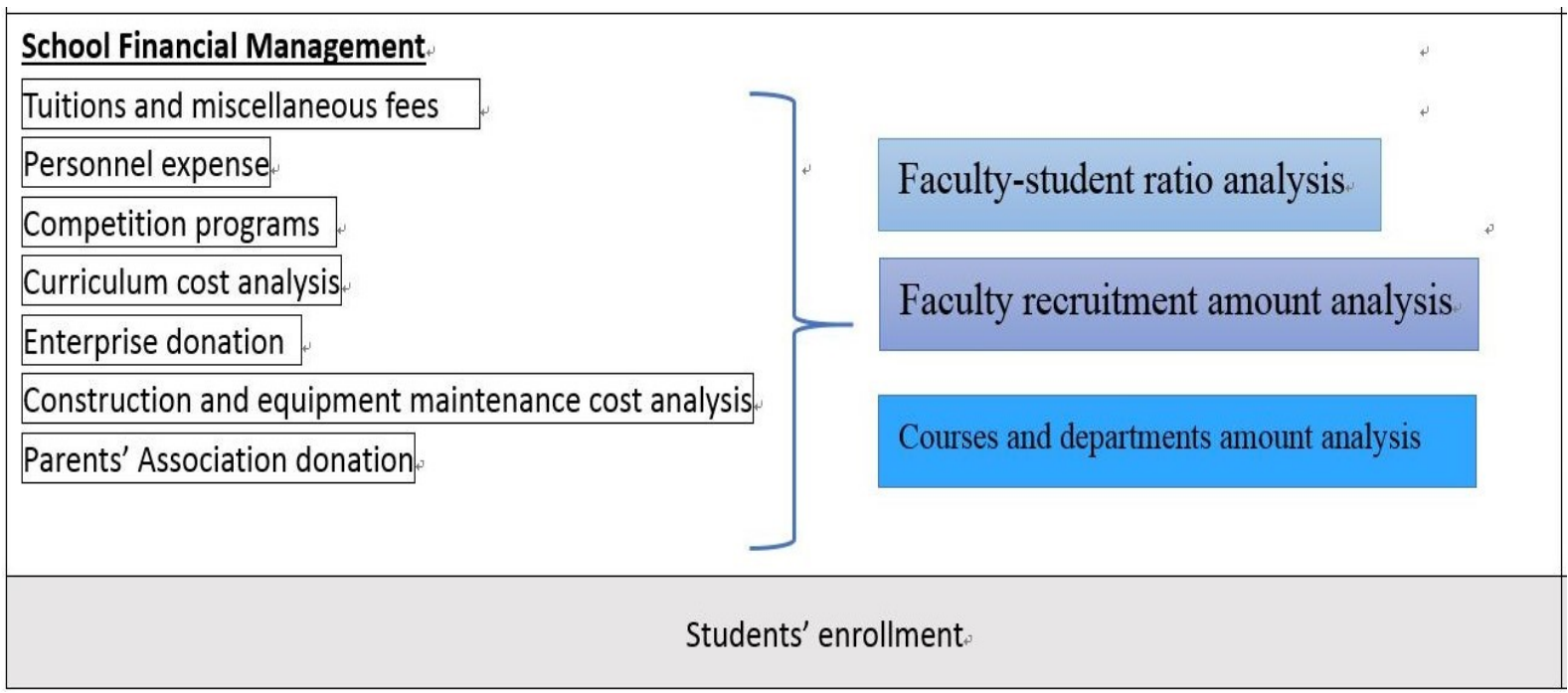

FIGURE 4. School financial management analysis module (Lin \& Lin, 2016) 
12. How to apply this Institutional Research model in senior high schools' financial function effectively?

In this study, we take the financial simulation analysis for example to demonstrate how to use the IR model. A new vision of senior high schools' financial management is hope- fully to be created. With this study, we also hope to exam our IR model's fitness and effectiveness. Figure 5 to Figure 7 show the results of our IR simulation work in schools' financial management.

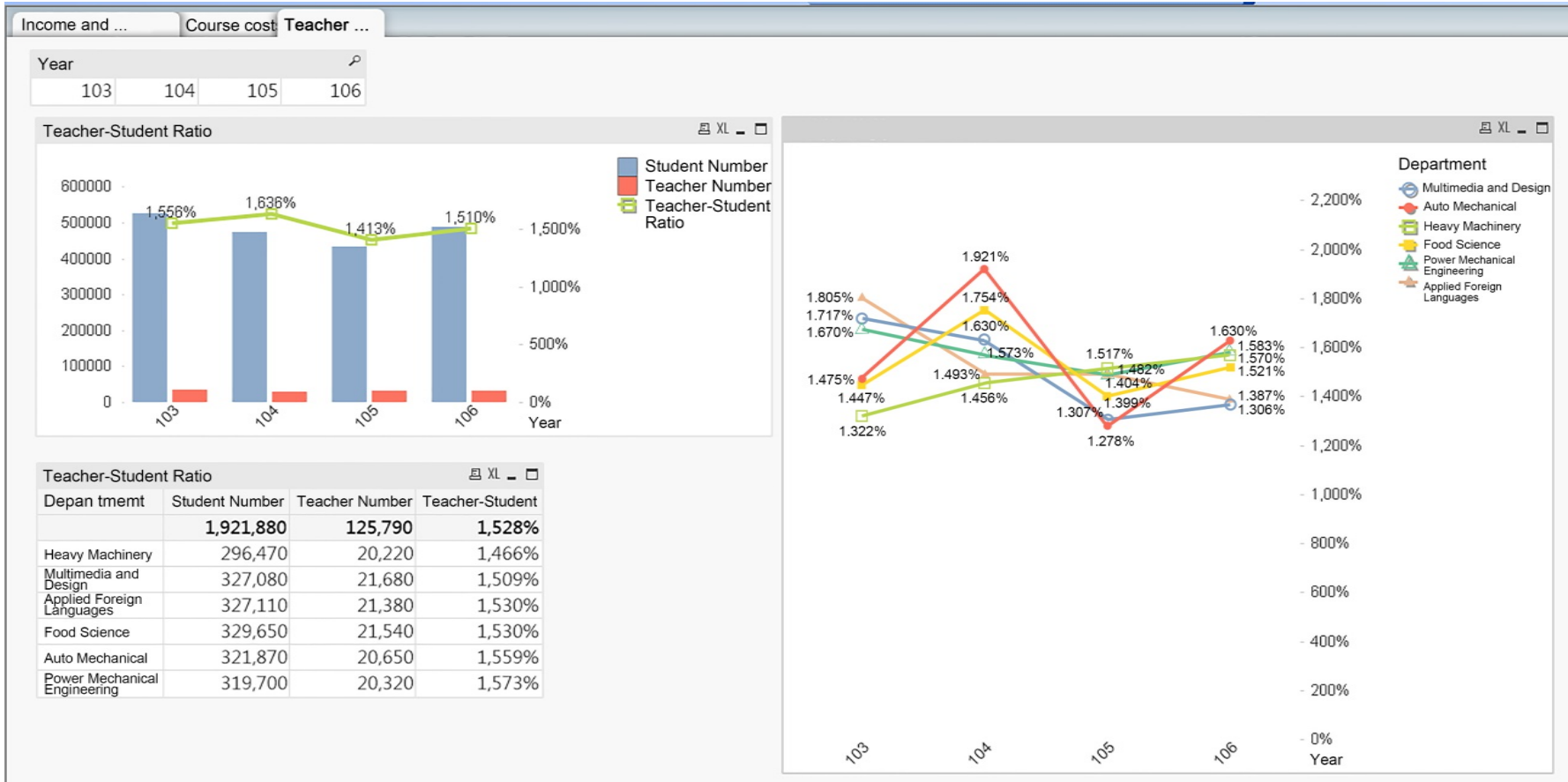

FIGURE 5. Student-teacher ratio simulation analysis

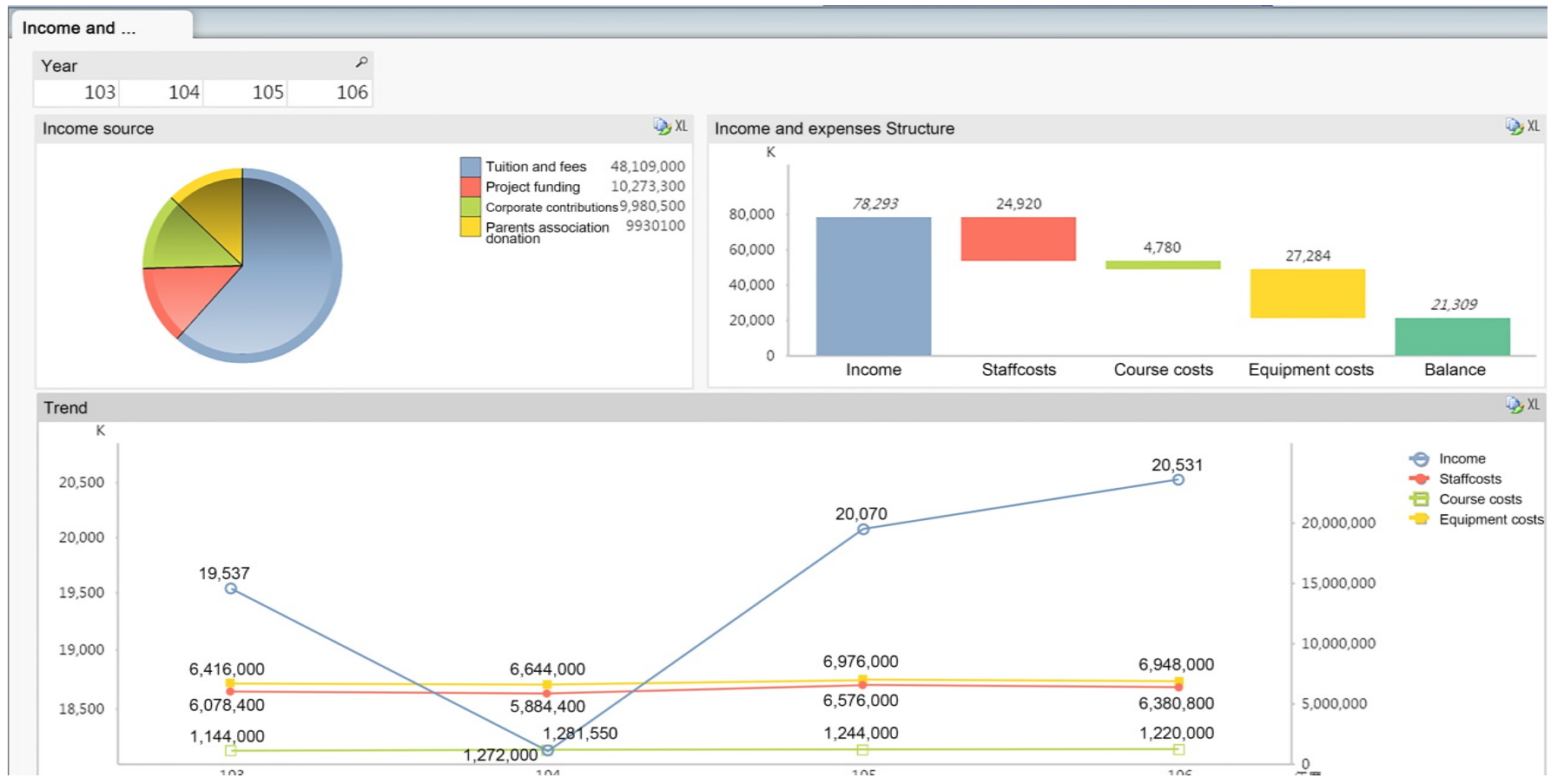

FIGURE 6. Income and expense simulation analysis 


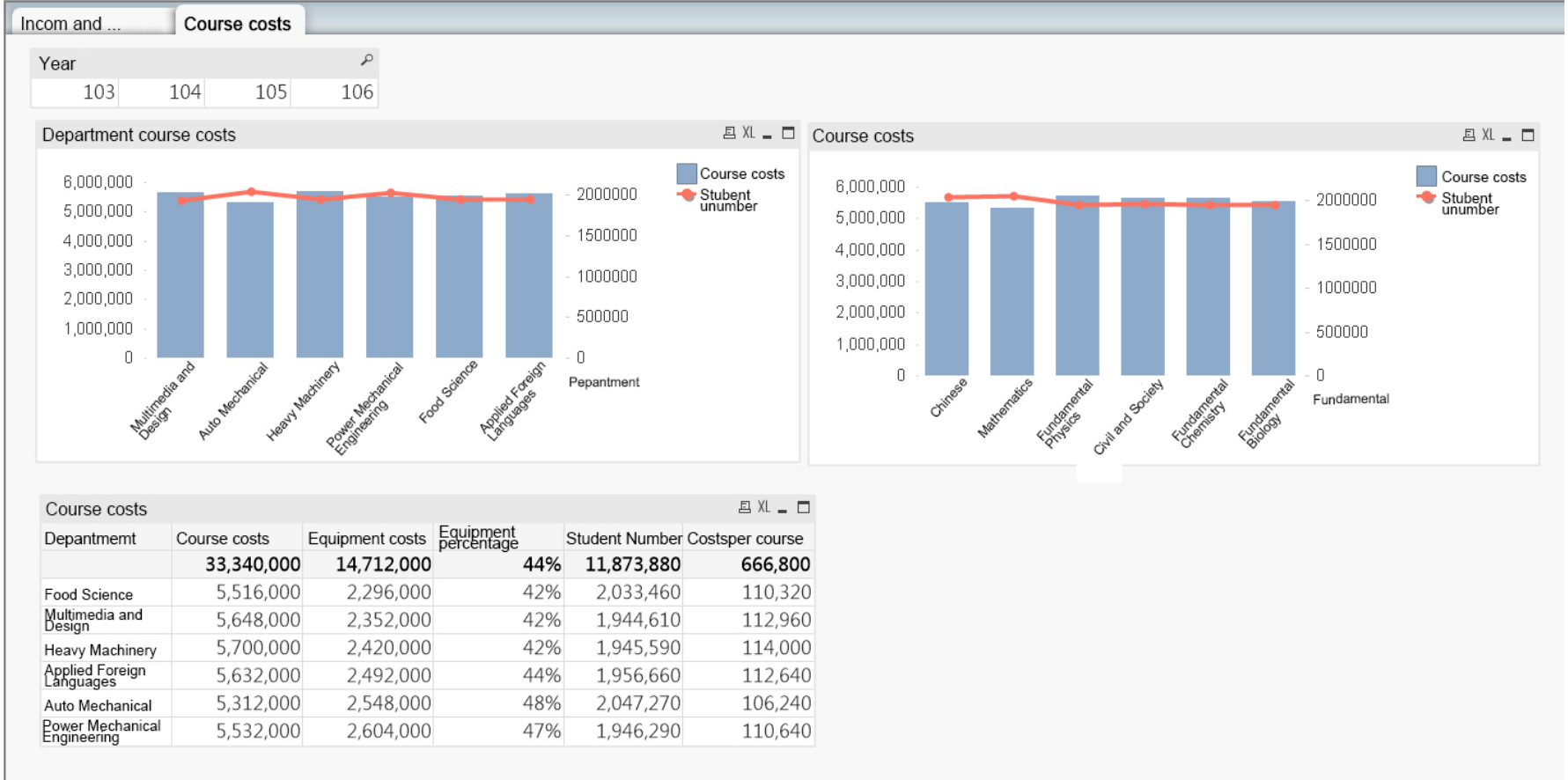

FIGURE 7. Course cost simulation analysis

\section{CONCLUSION AND SUGGESTIONS}

\section{Conclusion}

A brand-new, complete and overall Institutional Research model for senior high schools in Taiwan was proposed in 2016. This model divides into three stages including (1) students' enrollment, (2) school attendance and (3) graduates' career development stages as the developmental process after students enroll.

In this study, we take the financial simulation analysis for example to demonstrate how to use the IR model. A new vision of senior high schools' financial management is hopefully to be created. With this study, we also hope to exam our IR model's fitness and effectiveness.

\section{Suggestions}

1 More real data need to be collected and this IR model needs to be put into practice in the future study. After more examinations or tests, this IR model can be modified if needed.

2 Senior high schools are suggested to establish an IR office to be responsible for the IR work.

3 Long-term researches will offer more meaningful information for school management and IR researches' continuity is also necessary.

4 Senior high schools are suggested to grasp the KPI both of school evaluation and school education goals to develop their Institutional Research tasks.

\section{REFERENCES}

Association for Institutional Research. 2014. About air. URL: goo.gl/LoA49S. Last accessed on 23 March 2016. Chen L.M. 2004. A study of the improvement in financial system of private senior high and vocational schools in Taipei

city. Unpublished master's thesis, National Taiwan Normal University, Taipei, TW.

Chirikov, I. (2013). Research universities as knowledge networks: The role of institutional research. Studies in Higher

Ed- ucation, 38(3): 456-469. DOI: 10.1080/03075079.2013.773778

Laws and Regulations Database of the Republic of China. 2015. Act for establishing the national senior high school affairs

fund. URL: goo.gl/LBKTVw. Last accessed on 24 October 2016.

Li J.T. 1992. A study on tuition of university students and the government's subsidies to private universities and col- leges. Ministry of Education, Taipei, TW. 
Lin S.F., \& Lin Y.J. 2016a. A practical study on the school affairs decision system based on big data analysis. Paper presented at the meeting of The E-Learning and Information Technology Symposium, Southern Taiwan University of Sci- $\quad$ ence and Technology, Tainan, TW.

Lin S.F. \& Lin Y.J. 2016b. An exploratory study on senior high schools' institutional research model. Paper presented at the meeting of International Conference on Innovation of Education, Central Taiwan University of Science and Technol- $\quad$ ogy, Tainan, TW.

Liu S.Q. 1996. The review and adjustment of education financial system. Educational Information \& Research, 9: 30-35. Ministry of the Interior. 2016. Important indicators. URL: ggoo.gl/PGOc7Wc. Last accessed on 24 Januray 2017. Neave, G. 2003. Institutional research: From case study to strategic instrument in the dialogue between higher educa- tion research and practice. Netherlands, NL: Kluwer Academic Publishers. DOI: 10.1007/978-0-306-48368-4_1 Pathumporn, J., \& Nakapaksin, S. 2015. Participatory action research model for sustainable community based tourism de- $\quad$ velopment. International Journal of Business \& Administrative Studies, 1(3): 89- 93. D0I: 10.20469/ijbas.10002-3

Rijal, S. 2016. The influence of transformational leadership and organizational culture on learning organization: A compar- ative analysis of the IT sector Thailand. Journal of Administrative \& Business Studies, 2(3): 121-129.

DOI: $10.20474 /$ jabs-2.3.3

Saupe, J.L. 1981. The functions of institutional research. Tallahassee, FL: Association for Institutional Research. Taylor, J., Hanlon, M., \& Yorke, M. 2013. The evolution and practice of institutional research. New Directions for Institu- tional Research, 2013(157): 59-75. DOI: 10.1002/ir.20039

Terenzini, P.T. 1993. On the nature of institutional research and the knowledge and skills it requires. Research in Higher

Education, 34(1): 1-10. D0I: 10.1007/BF00991859

Visual Intelligence. 2016. What is QlikView? URL: goo.gl/IE3Sd7. Last accessed on 20 Februray 2017.

Volkwein, F. 2015. Teaching and learning in IR courses: Myths vs. reality. Paper presented at the Forum of the Associa- $\quad$ tion for Institutional Research, Denver, CO.

Webber K., Calderon, A., Nauffal, D., Saavedra, M., Bramblett, S., \& Borden. V. 2015. IR in the world around us. Paper pre- $\quad$ sented at the Forum of the Association for Institutional Research, Denver, CO. 